\title{
The Effect of Proteoglycans on the Formation of Fibrils from Collagen Solutions ${ }^{1}$
}

\author{
THEODORE R. OEGEMA, JR., JANA LAIDLAW, VINCENT C. HASCALL, ${ }^{2}$ AND \\ DOMINIC D. DZIEWIATKOWSKI
}

The Departments of Oral Biology and Biological Chemistry and The Dental Research Institute, The
University of Michigan, Ann Arbor, Michigan 48104

Received March 25, 1975

\begin{abstract}
The precipitation of collagen fibrils from solutions at $37^{\circ} \mathrm{C}$ and approximately physiological pH and ionic strength is retarded markedly in the presence of small amounts of proteoglycan monomer (PGS), proteoglycan aggregate (PGC), reduced and alkylated PGS, or cyanogen bromide-cleavage products of PGS. The polysaccharide-peptide fragments produced from PGS with papain, trypsin, cathepsin D, or the protein core obtained by the digestion of PGS with chondroitinase $A B C$ are ineffective in this regard. In the presence of the materials which affected the rate of precipitation of the collagen fibrils, the specific absorbance, $\Delta A_{\text {sp }}$, of the collagen gels was directly related to specific retardation, $\boldsymbol{R}_{\mathrm{sp}}$, when the ratio of proteoglycan to collagen was less than $25 \mu \mathrm{g} / \mathrm{mg}$, suggesting that the size and/or organization of the fibrils in the gels was dependent on the presence of proteoglycans. PGS binds to collagen if it is present in the solution before the collagen fibrils form and at a maximum of about 1 molecule of PGS for every 25-30 molecules of collagen. Although the protein core of PGS does not retard fibrillogenesis, it does bind to collagen and does so even in the presence of PGS. The data support the thesis that the organization of collagen fibrils in tissues may be related to amounts and kinds of proteoglycans in the tissues.
\end{abstract}

In 1937, Meyer et al. $(1,2)$ studied the composition and properties of insoluble complexes formed between gelatin and chondroitin sulfate. The stoichiometry of the complexes suggested that they were salts involving the basic amino acid residues in gelatin and the sulfate and carboxy groups in the glycosaminoglycan. From a comparison of the solubility of these complexes in solutions of $\mathrm{CaCl}_{2}$ and the extractability of "chondroitin sulfates" from tissues with solutions of $\mathrm{CaCl}_{2}$, they proposed that the major portion of the matrix in cartilages "is a protein salt of chondroitin sulfuric acid." The protein was thought to be collagen. Since this pioneering effort to explain the characteristics of

${ }^{1}$ This work was supported by the National Institute of Dental Research (Grant No. DE 02731).

${ }^{2}$ Present address: National Institute of Dental Research, National Institutes of Health, Bethesda, MD 20014. the cartilage matrix in terms of the chemical properties of its two major components, many workers have studied the interactions of glycosaminoglycans and proteoglycans with collagen.

Vanamee and Porter (3), Jackson and Fessler (4) and Gross et al. (5) found that solubilized collagens could be reprecipitated from solution to give fibrils with an apparently native structure. Moreover, it was suggested by Gross (6) that glycosaminoglycans might play a role in the organization of collagen fibrils. Gross and Kirk (7) subsequently developed a procedure whereby the kinetics of collagen precipitation in the presence of additives could be studied. They found that hyaluronic acid, chondroitin sulfate and $\alpha_{1}$-glycoprotein did not influence the rate or extent of collagen precipitation. In kinetic studies on the formation of fibrils from collagen solutions, Wood and Keech (8) observed that the rate 698

Copyright (C) 1975 by Academic Press, Inc.

All rights of reproduction in any form reserved. 
of precipitation varied with $\mathrm{pH}$, ionic strength and temperature. Further, Wood and Keech (8) found that as the rate of precipitation decreased, the width of the fibrils, as seen in an electron microscope, increased. Thereafter, Wood (9) and Keech (10) reported that chondroitin-4-sulfate, chondroitin-6-sulfate and keratan sulfate very slightly accelerated fibril formation, whereas dermatan sulfate and hyaluronic acid had no effect. Heparin and deoxyribonucleic acid at low concentrations retarded the formation of collagen fibrils, and the fibrils were wider than those formed in the absence of glycosaminoglycans or in the presence of chondroitin-4-sulfate, chondroitin-6-sulfate or keratan sulfate. On the other hand, Mathews and Decker (11) found that the collagen fibrils formed in the presence of heparin had smaller diameters than those formed in the presence of proteoglycans. The effectiveness of the cartilage proteoglycans in retarding fibrillogenesis was related to their size (11).

Wood and Keech (8), on the basis of an analysis of their kinetic data on the formation of fibrils from solutions of collagen, suggested that precipitation occurs in two consecutive phases, namely, a nucleation phase and a growth phase. Wood (9) then derived equations which described these consecutive steps and suggested a relationship between the final turbidity $\left(E_{\infty}\right)$ and the width of the fibrils in the gels.

More recently, Toole and Lowther (12) demonstrated that the rate of formation of fibrils in solutions of collagen is markedly delayed in the presence of very small amounts of proteoglycan monomers. Furthermore, they showed that about $60 \%$ of the collagen molecules reacted with the proteoglycan monomers at $4^{\circ} \mathrm{C}$. Such proteoglycan-collagen aggregates could be removed by centrifugation at $4^{\circ} \mathrm{C}$ and the remainder of the collagen, while capable of transformation into fibrils, did so only after prolonged incubation at $37^{\circ} \mathrm{C}$.

In an extension of the work of Toole and Lowther (12), Lowther and Natarajan (13) reported that, although monomeric forms of proteoglycans inhibited fibrillogenesis in solutions of collagen at $37^{\circ} \mathrm{C}$, the aggregated forms of the same proteoglycans did not.
The studies reported here were undertaken to determine additional characteristics of the interactions of collagens and proteoglycans.

\section{MATERIALS AND METHODS}

Materials. Chondroitinase ABC was purchased from Miles Research; crystalline papain and crystalline trypsin from Worthington Biochemicals; carrier-free $\left[{ }^{35} \mathrm{~S}_{\mathrm{SO}_{4}}\right.$ and $\mathrm{L}_{-}\left[{ }^{3} \mathrm{H}\right]$ serine from New England Nuclear; Soluene from Hewlett-Packard.

Buffers. The buffer described by Toole and Lowther (12) was used. It was prepared at $10 \times$ the concentration specified by them and diluted for use. The $\mathrm{pH}$ of the diluted $1 \times$ buffer $(0.14 \mathrm{~m} \mathrm{NaCl}, 0.008$ $\mathrm{M} \mathrm{Na}_{2} \mathrm{HPO}_{4} / \mathrm{KH}_{2} \mathrm{PO}_{4}$ ) at $25^{\circ} \mathrm{C}$ was $7.3-7.5$, whereas the $\mathrm{pH}$ of the concentrated buffer was about 6.9. All buffers were kept at $4^{\circ} \mathrm{C}$.

Collagen. Collagen was isolated from bovine fetal skin at $4^{\circ} \mathrm{C}$ as suggested by Piez et al. (14). The coarsely ground tissue was first extracted with 15

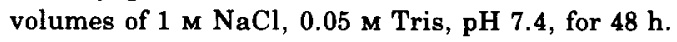
The collagen thus extracted was not used in the experiments. The residue was separated from the extract by filtration through surgical gauze and further extracted for $72 \mathrm{~h}$ with 15 volumes of $0.5 \mathrm{M}$ acetic acid. The extract was again separated by filtration through surgical gauze. The latter extract was further clarified by filtration through a layer of Celite on a large Buchner funnel. From this clarified extract the collagen was precipitated by the addition of solid sodium chloride to a final concentration of $5 \%(w / v)$. The precipitated collagen was isolated by centrifugation. It was dissolved in $0.5 \mathrm{M}$ acetic acid and reprecipitated by dialysis against $0.02 \mathrm{M}$ sodium phosphate, $\mathrm{pH}$ 7.4. The precipitated collagen was again dissolved in $0.5 \mathrm{M}$ acetic acid and the solution was adjusted to $0.1 \mathrm{M}$ acetic acid by extensive dialysis against $0.1 \mathrm{M}$ acetic acid. After lyophilization, when a portion of the dried collagen was chromatographed on carboxymethylcellulose according to Piez et al. (14) only $\alpha$ and $\beta$ components at a ratio of about 1 to 2 were found.

Preparations of proteoglycans. Proteoglycan monomer (PGS) $^{3}$ and proteoglycan aggregate (PGC) were isolated from bovine nasal cartilage as previously described (15). A proteoglycan monomer was also isolated from the Swarm rat chondrosarcoma as described elsewhere (16) either without an isotopic label or at $24 \mathrm{~h}$ after the injection of $2 \mathrm{mCi}$ of carrierfree $\left[{ }^{35} \mathrm{~S}\right]$ sulfate or $400 \mu \mathrm{Ci}$ of $\left[{ }^{3} \mathrm{H}\right]$ serine into developing tumors of about $10 \mathrm{~g}$ in weight. These preparations were dialyzed extensively at $4^{\circ} \mathrm{C}$ against $0.1 \mathrm{M}$ potassium acetate, $\mathrm{pH} 7,0.1 \mathrm{~m}$ sodium sulfate, $\mathrm{pH} 7$, and $\mathrm{H}_{2} \mathrm{O}$ before lyophilization.

Column chromatography. The relative sizes of

${ }^{3}$ Abbreviations used: PGS, proteoglycan monomer; PGC, proteoglycan aggregate. 
the derivatives of proteoglycan monomer were determined by permeation through $0.9 \times 180-\mathrm{cm}$ colums of Sepharose 2B, $4 B$ and $6 B$ (16). The columns were equilibrated and eluted with $0.5 \mathrm{M}$ sodium acetate, pH 7.0. Uronic acid and protein in the fractions were determined by automated procedures (17).

Preparation of derivatives of proteoglycans. Chondroitin $\left.{ }^{35} \mathrm{~S}\right]$ sulfate was isolated from papain digests of the ${ }^{35} \mathrm{~S}$-labeled proteoglycan monomer of the Swarm rat chondrosarcoma by the procedure of Antonopoulos et al. (18).

The protein core of the $\left[{ }^{3} \mathrm{H}\right]$ serine-labeled PGS was isolated after digestion with chondroitinase ABC of the $\left[{ }^{3} \mathrm{H}\right]$ PGS from the Swarm rat chondrosarcoma (19). The digest was dialyzed extensively against a buffer, which contained $0.1 \mathrm{~mol}$ of sodium acetate and $0.1 \mathrm{~mol}$ of Tris per liter and was adjusted to $\mathrm{pH} 7.4$ with acetic acid, to remove products of low molecular weighi. The protein core was further purified by chromatography on Sepharose 4B. The single, included peak, $K_{\mathrm{av}}=0.60$, was recovered and dialyzed extensively against $\mathrm{H}_{2} \mathrm{O}$ before lyophilization.

PGS, $100 \mathrm{mg}$, from bovine nasal cartilage, was dissolved in $20 \mathrm{ml}$ of $0.1 \mathrm{M}$ Tris, $\mathrm{pH} 7.6$, which was also $0.05 \mathrm{M}$ in calcium acetate. To this solution, $5 \mathrm{mg}$ of trypsin in $1 \mathrm{ml}$ of $0.001 \mathrm{~N} \mathrm{HCl}$ were added. The solution was incubated at $37^{\circ} \mathrm{C}$ for $4 \mathrm{~h}$, by which time the viscosity of the incubation mixture had been at a limit value for $3 \mathrm{~h}$. To the digest, $\mathrm{CsCl}$ was added to a density of 1.466 . After centrifugation at $40,000 \mathrm{rpm}$ for $48 \mathrm{~h}$, the lower two-fifths of the gradient was isolated and dialyzed extensively against water, 0.1 $M$ potassium acetate and then water at $4^{\circ} \mathrm{C}$. The retained solution was lyophilized. A broad included peak, $K_{\text {av }}=0.17$, was found on permeation of a portion of the lyophilized material through Sepharose $6 \mathrm{~B}(20)$.

Proteoglycan monomer ( $100 \mathrm{mg}$ ) from bovine nasal cartilage was dissolved in $20 \mathrm{ml}$ of $0.1 \mathrm{M}$ potassium acetate buffer, $\mathrm{pH}$ 4.0. Cathepsin $\mathrm{D}$ isolated from beef liver according to Barrett (21), $1 \mathrm{mg}$ in 1 $\mathrm{ml}$ of the buffer, was added and the mixture was incubated at $37^{\circ} \mathrm{C}$ for $7 \mathrm{~h}$, by which time the viscosity had been at a limit value for $1 \mathrm{hr}$. The product was isolated from a density gradient as described above. On permeation of a portion of the lyophilized preparation through Sepharose $6 \mathrm{~B}(20)$, a single symmetrical peak, $K_{\mathrm{av}}=0.14$, was found.

Proteoglycan monomer from bovine nasal cartilage was treated with cyanogen bromide as described by Ikenaka et $a l$. (22) and lyophilized. On permeation through Sepharose 2B (20), an asymmetric peak, $K_{\mathrm{av}}=0.41$, was found.

Proteoglycan monomer from bovine nasal cartilage was also reduced with dithiothreitol and alkylated with iodoacetamide (15). The preparation was dialyzed extensively against water, $0.1 \mathrm{M}$ potassium acetate and then water at $4^{\circ} \mathrm{C}$. The retained solution was lyophilized. On permeation of a portion of the lyophilized preparation through Sepharose $2 B$, a single symmetrical peak, $K_{\mathrm{av}}=0.25$, was found.

Concentrations of collagen in solutions were calculated on the basis of hydroxyproline contents, which were determined by the method of Neuman and Logan (23), having first determined by the use of an amino acid analyzer $(24,25)$ that $11 \%$ of the collagen preparation was hydroxyproline. Concentrations of the proteoglycans were estimated on the basis of hexuronic acid, which was determined by a procedure utilizing carbazole (26). Concentrations of the proteoglycan core were estimated by measuring protein according to Lowry et al. (27).

Collagen and proteoglycan solutions. Collagen was dissolved in $0.5 \mathrm{M}$ acetic acid at $4^{\mathrm{C}} \mathrm{C}$ to an approximate concentration of $2 \mathrm{mg} / \mathrm{ml}$. Such solutions were dialyzed extensively at $4^{\circ} \mathrm{C}$ either against 1) $0.005 \mathrm{M}$ acetic acid or 2) the diluted, $1 \times$, phosphate buffer. Dilutions were made with either $0.005 \mathrm{M}$ acetic acid or the $1 \times$ phosphate buffer on the basis of hydroxyproline content to give solutions of the desired concentrations.

Samples of the proteoglycans were dissolved in and extensively dialyzed against the $1 \times$ dilute phosphate buffer.

Precipitation of collagen. Method A. Solutions of collagen in $0.005 \mathrm{M}$ acetic acid were prepared at twice the final concentration to be used in the experiments. They were then kept at room temperature for $2 \mathrm{~h}$. For each experiment, a $250-\mu \mathrm{l}$ aliquot of a test sample of a proteoglycan in $1 \times$ buffer and a $250-\mu$ l aliquot of $3 \times$ buffer were placed in a $1-\mathrm{ml}$ quartz cuvette with a light path of $1 \mathrm{~cm}$. The aliquot of $3 \times$ buffer contained a stoichiometric amount of $\mathrm{NaOH}$ to neutralize the acetic acid in $500 \mu \mathrm{l}$ of the collagen solution. Fibrillogenesis was initiated by adding 500 $\mu l$ of a collagen solution to the cuvette and mixing the contents thereof rapidly for about $15 \mathrm{~s}$ by drawing the solution back and forth several times into a Pasteur pipet. Immediately thereupon, the cuvettes were placed in a spectrophotometer, ${ }^{4}$ and the change in absorbance at $400 \mathrm{~nm}$ with time was recorded. The temperature of the cuvettes rose to $37^{\circ} \mathrm{C}$ within 2 min and was maintained at this temperature during the course of an experiment. For these experiments the cuvettes were cleaned with a mild detergent, soaked in aqua regia, rinsed in glass-distilled water and air dried.

${ }^{4}$ An Acta III (Beckman) in which the sample compartment was thermostatically controlled was used in conjunction with an automatic sampling system for most of the experiments. Some of the experiments were done with Unicam 700 in which the temperature of the sample compartment was thermostatically controlled. 
Method $B$. At $4^{\circ} \mathrm{C}, 1 \mathrm{ml}$ of the $1 \times$ buffer, with or without a proteoglycan, was added to a precooled test tube that contained $2 \mathrm{ml}$ of a solution of collagen in $1 \times$ buffer. After mixing, the solution was transferred to a precooled $3 \mathrm{ml}$ quartz cuvette that then was placed in a spectrophotometer at $37^{\circ}$. The change in absorbance at $400 \mathrm{~nm}$ with time was recorded.

Binding of labeled proteoglycans to collagen. The experiments were done with different final concentrations of collagen as in Method $A$ of Precipitation of collagen, except that labeled preparations, either ${ }^{35} \mathrm{~S}$-labeled PGS or ${ }^{3} \mathrm{H}$-labeled core, were used. At the end of the experiments, the gels were transferred from the cuvettes to polyallomer tubes and were centrifuged at top speed in a clinical centrifuge for $15 \mathrm{~min}$ at $37^{\circ} \mathrm{C}$. The radioactivities in aliquots of the supernatant solutions, as well as in aliquots of the solutions of labeled materials before mixing with the collagen solutions, were determined in Soluene cocktails with a Beckman scintillation counter.

As an extension of the above, gels formed from solutions which contained $1.2 \mathrm{mg}$ of collagen per $\mathrm{ml}$ and $150 \mu$ of ${ }^{35} \mathrm{~S}$-labeled PGS per ml were compacted by centrifugation and washed once with $1 \mathrm{ml}$ of $1 \times$ buffer in the centrifuge at $37^{\circ} \mathrm{C}$. They were resuspended in $1 \mathrm{ml}$ of the same buffer, which contained varying amounts of unlabeled PGS. After incubation at $37^{\circ} \mathrm{C}$ for $16 \mathrm{~h}$, the gels were pelleted by centrifugation and radioactivities in the supernatant fractions were determined.

Also, collagen gels were formed from solutions that contained $1.2 \mathrm{mg}$ of collagen per $\mathrm{ml}$ and $30 \mu \mathrm{g}$ of unlabeled PGS per ml. After centrifugation the gels were resuspended in $1 \mathrm{ml}$ of $1 \times$ buffer, which contained different concentrations of the ${ }^{35} \mathrm{~S}$-labeled PGS. After incubation for $16 \mathrm{~h}$ at $37^{\circ} \mathrm{C}$, the gels were pelleted by centrifugation and radioactivities in the supernatant fractions were determined.

Collagen was also precipitated from solutions which contained $1.2 \mathrm{mg}$ collagen per $\mathrm{ml}$ and $\left[{ }^{3} \mathrm{H}\right]$ serine-labeled core of the PGS, equivalent to 150 $\mu \mathrm{g}$ of PGS per $\mathrm{ml}$, in the presence of varying amounts, 0-1 mg, of unlabeled PGS to determine if there was competition for binding sites. The collagen gels were pelleted by centrifugation and the radioactivities in the supernatant fractions were determined.

\section{RESULTS}

\section{Definition of Parameters}

The rate of fibril formation in the collagen solutions was followed by observing the change in absorbance at $400 \mathrm{~nm}$ with time $(7,8,13)$. The changes in absorbance in a representative experiment are shown in Fig. 1. There is a lag, or nucleation, phase followed by a rapid phase of fibril formation and growth, during which the absorbance increases until a limiting value is reached. The two measurements used for the calculations described in this report are also indicated in Fig. 1: the net change in absorbance, $\Delta A$ (or $\Delta A^{0}$ for samples with no added proteoglycan) and the time to reach one-half of $\Delta A, t_{1 / 2}$ (or $\mathrm{t}^{0}{ }_{1 / 2}$ ). These values were used to calculate the specific change in absorbance, $\Delta A_{\mathrm{sp}}$, and the specific retardation of fibril formation, $R_{\mathrm{sp}}$, where

$$
\left.A_{\mathrm{sp}}=\left(\Delta \mathrm{A}-\Delta A_{0}\right) / \Delta A_{0}\right)
$$

and

$$
\left.R_{\mathrm{sp}}=\left(t_{1 / 2}-t^{0}{ }_{1 / 2}\right) / t^{0}{ }_{1 / 2}\right)
$$

The specific retardation, $R_{\mathrm{sp}}$, is related to the retardation factor $(R)$ described by $\mathrm{Ma}-$ thews and Decker (11) and to the $t_{0.5}$ described by Wood and Keech (8). The $\Delta A$ is comparable to $E_{\infty}$ of Wood and Keech (8).

\section{The effect of Proteoglycan Monomer on $\Delta A_{s p}$}

The effect of the PGS isolated from bovine nasal cartilage on the specific change in absorbance $\left(\Delta A_{\mathrm{sp}}\right)$ was determined at four different final concentrations of colla-

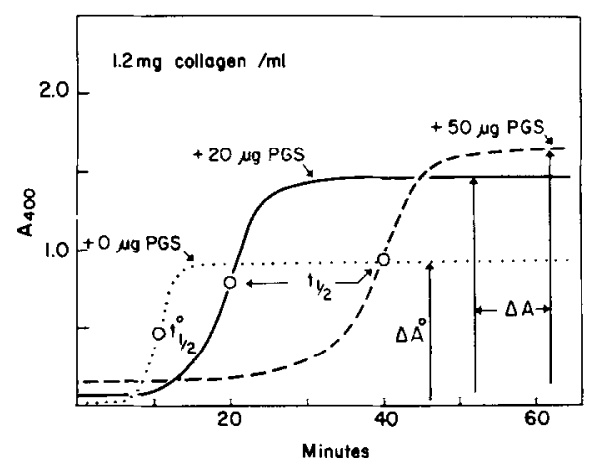

FiG. 1. The effect of proteoglycan monomer (PGS) on the gelation of collagen. Three identical solutions of collagen in the presence or absence of PGS were adjusted to $\mathrm{pH} 7.3$ and the temperature was raised to $37^{\circ} \mathrm{C}$. The formation of collagen fibrils was determined by measuring the change in absorbance at $400 \mathrm{~nm}$ with time. The indicated parameters were calculated from each run as described in the text. 
gen, $0.3,0.6,0.9$ and $1.2 \mathrm{mg} / \mathrm{ml}$. The data for the 0.6 and $1.2 \mathrm{mg} / \mathrm{ml}$ concentrations are shown in Fig. 2. The $\Delta A_{\text {sp }}$ increased rapidly on addition of small amounts of PGS until a maximum value was reached, after which it decreased in all cases as the concentration of PGS was increased. The maximum value for $\Delta A_{\mathrm{sp}}$ in each of the experiments was obtained at a concentration of $50-60 \mu \mathrm{g}$ of PGS/mg of collagen (Table I).

The data in the rising portions of the curves in Fig. 2 were further analyzed by the method of Lineweaver and Burk (28) (Fig. 3). At all collagen concentrations these plots of reciprocals yielded straight

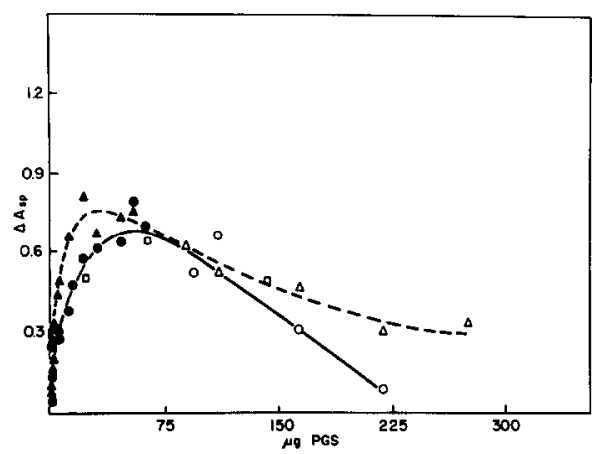

FIG. 2. Relation of specific change in absorbance $\left(\Delta A_{s p}\right.$ ) of collagen gels to concentration of PGS and PGC. In one series of experiments, and $O$, the solutions contained $1.2 \mathrm{mg}$ collagen per $\mathrm{ml}$ and indicated concentrations of PGS $(\mu \mathrm{g} / \mathrm{ml})$. In the other series, $\Delta$ and $\Delta$, the concentration of collagen was $0.6 \mathrm{mg} / \mathrm{ml}$. The effect of PGC on $\Delta A_{\mathrm{sp}}$, when the concentration of collagen was $1.2 \mathrm{mg} / \mathrm{ml}$, is shown as $\square$. The data in the rising portion of each curve (solid symbols) are presented in the form of reciprocal plots in Fig. 3. lines which very nearly intercepted the abscissa at a common point. The negative reciprocals of these intercepts (Table I) indicate that 5-6 $\mu \mathrm{g}$ of $\mathrm{PGS} / \mathrm{ml}$ were sufficient to produce half of the maximal $\Delta A_{\mathrm{sp}}$. Additionally, the reciprocals of the intercepts at the ordinate, which are an indication of the expected maximal values for $\Delta A_{\mathrm{sp}}$, are close to each other (Table I). They agree with the observed values shown in Fig. 2.

As reported by others $(7,8)$ the absorbance of the collagen gels in the absence of added proteoglycan, $\Delta A^{0}$, was directly proportional to the concentration of collagen (Table I). The data on the mixtures of colla-

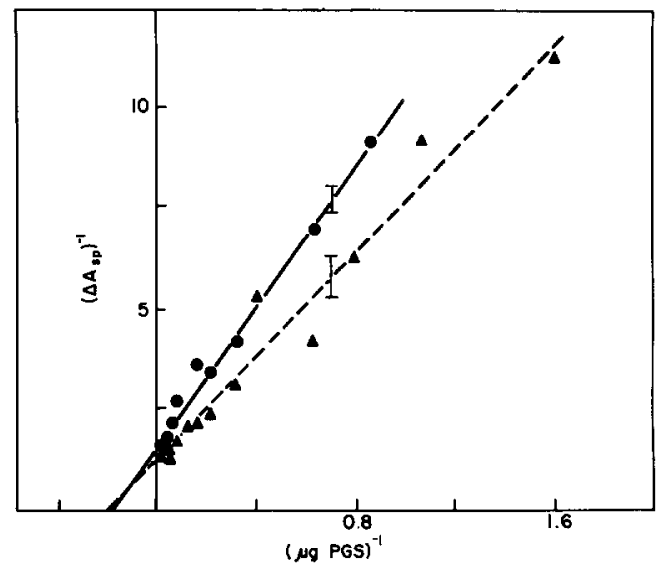

Fig. 3. Relation of the reciprocal of the specific change in absorbance of collagen gels to the reciprocal of the concentration of PGS which affected the absorbance. The symbols are as described in the legend to Fig. 2. The vertical bars indicate the standard error of estimate for the data from the best least squares lines. Values for the intercepts at the abscissa and ordinate are given in Table $\mathrm{I}$.

\section{TABLE I}

Fffect of Proteoglycan Monomer (PGS) on the Change in Specific Absorbance of Collagen Gels, $\Delta A_{\mathrm{sp}}$

\begin{tabular}{|c|c|c|c|c|c|}
\hline $\begin{array}{l}\text { Final collagen } \\
\text { concentration } \\
(\mathbf{m g} / \mathbf{m l})\end{array}$ & $\Delta A^{\circ}$ at $400 \mathrm{~nm}$ & $\Delta A_{\mathrm{sD}}(\max )$ & $\begin{array}{c}\text { PGS/collagen at } \\
\Delta A_{\mathrm{gp}}(\max ) \\
(\mu \mathrm{g} / \mathrm{mg})\end{array}$ & $\begin{array}{c}\text { Negative reciprocal } \\
\text { on abscissa for } \Delta A_{\mathrm{gp}}{ }^{a} \\
\text { ( } \mu \mathrm{g} \text { of } \mathrm{PGS})\end{array}$ & $\begin{array}{c}\text { Reciprocal at } \\
\text { ordinate for } \\
\qquad \Delta \mathbf{A s p}^{a}\end{array}$ \\
\hline 0.3 & $0.248 \pm 0.011$ & 0.85 & $60-80^{b}$ & 5.3 & 0.85 \\
\hline 0.6 & $0.414 \pm 0.019$ & 0.80 & 60 & 5.3 & 0.85 \\
\hline 0.9 & $0.640 \pm 0.017$ & 0.70 & 55 & 5.3 & 0.78 \\
\hline 1.2 & $0.848 \pm 0.052$ & 0.75 & 50 & 5.6 & 0.67 \\
\hline
\end{tabular}

\footnotetext{
a From best least squares lines as in Fig. 3.

$b$ This value is uncertain because of scatter in data.
} 
gen and PGS, then, indicate that when PGS is present the $\Delta A$ is a reflection of the PGS to collagen ratio instead of the absolute concentration of PGS, since the maximum value of $\Delta A_{\mathrm{sp}}$ was about the same for all concentrations of collagen.

In the experiments in which a change in temperature, Method $B$, was used to initiate fibril formation instead of a $\mathrm{pH}$ change, Method $A$, the $\Delta A_{\text {sp }}$ was also dependent on the concentration of PGS. However, the maximal effect was usually smaller and varied with the age of the collagen solution. This was primarily due to an increase in $\Delta A^{0}$ values with time. It is possible that this was due to increased nucleation or organization of the collagen molecules at $4^{\circ} \mathrm{C}$ and $\mathrm{pH} 7.3$ with time. Unlike the $\Delta A_{\text {sp }}$, however, $R_{\text {sp }}$ described below was not appreciably different in the experiments on gelation conducted by Methods $A$ or $B$.

\section{The Effect of Proteoglycan Monomer (PGS) on Specific Retardation of Collagen Gelation}

The specific retardation of collagen gelation $\left(\boldsymbol{R}_{\mathrm{sp}}\right)$ increased rapidly in the presence of increasing amounts of PGS (Fig. 4) until a maximum effect was attained. Thereaf- ter, $R_{\text {sp }}$ decreased slightly. The maximum values for $R_{\mathrm{sp}}$ were related to the concentration of collagen, but, when normalized, occurred at about $100-130 \mu \mathrm{g}$ of PGS/mg of collagen in each case (Table II). The data in the rising portions of the curves (solid symbols) were replotted as reciprocals (Fig. 5). Thereby, it became apparent that the effect of PGS on the gelation of collagen is at least biphasic. At low concentrations of PGS, below $30 \mu \mathrm{g}$, the reciprocal plots were linear (solid symbols). At intermediate concentrations of PGS, $30-200 \mu \mathrm{g}$, the data (half-solid symbols) indicated that, even though $R_{\text {sp }}$ continued to increase as the concentration of PGS was increased, the increments of increase progressively decreased. The best straight lines through the data for low concentrations of PGS are indicated. The values of the reciprocals for the intercepts of these lines at the abscissa, given in Table II, indicate that the early retardation phase is "half-saturated" by about 2-5 $\mu \mathrm{g}$ of PGS/ml, independent of the concentration of collagen. The second phase requires much higher concentrations of PGS.

Although the uncertainty in the time required to reach the final temperature of $37^{\circ} \mathrm{C}$ in these experiments did not allow for

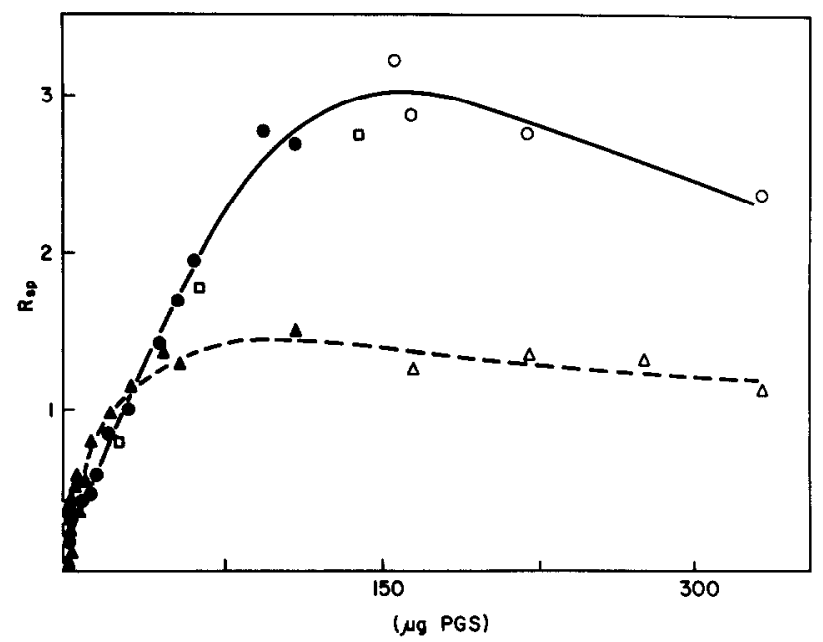

Fig. 4. Relation of specific retardation of collagen gelation $\left(R_{\mathrm{sp}}\right)$ to concentration of PGS and PGC. The specific setardation, $R_{s p}$, is defined in the text. In one series of experiments the collagen concentration was $1.2 \mathrm{mg} / \mathrm{ml}$, and $O$, and in the other series of experiments it was $0.6 \mathrm{mg} / \mathrm{ml}, \Delta$ and $\triangle$. The effect of PGC on $R_{\mathrm{sp}}$, when the concentration of collagen was 1.2 $\mathrm{mg} / \mathrm{ml}$, is shown as $\square$. The data indicated by the solid symbols are also given in the form of reciprocal-reciprocal plots in Fig. 5. 


\section{TABLE II}

Effect of Proteoglycan Monomer (PGS) on Specific Retardation of Collagen Gelation, $\boldsymbol{R}_{\mathrm{sp}}$

\begin{tabular}{|c|c|c|c|c|c|}
\hline $\begin{array}{l}\text { Final collagen } \\
\text { concentration } \\
(\mathbf{m g} / \mathrm{ml})\end{array}$ & $\mathbf{t}^{\circ}(\min )$ & $R_{\mathrm{sp}}(\max )$ & $\begin{array}{c}\text { PGS/collagen at } \\
R_{\mathrm{sp}}(\max )(\mu \mathrm{g} / \mathrm{mg})\end{array}$ & $\begin{array}{l}\text { Negative reciprocal } \\
\text { at abscissa for } R_{\mathrm{sv}}{ }^{a}\end{array}$ & $\begin{array}{c}\text { Reciprocal at } \\
\text { ordinate for } \\
\boldsymbol{R}_{\mathbf{s p}}{ }^{a}\end{array}$ \\
\hline 0.3 & $20.52 \pm 1.40$ & 0.9 & 170 & $2.0^{b}$ & .63 \\
\hline 0.6 & $13.42 \pm 1.59$ & 1.6 & 140 & 4.2 & .98 \\
\hline 0.9 & $11.34 \pm 0.28$ & 2.6 & 155 & 4.8 & .94 \\
\hline 1.2 & $11.03 \pm 0.79$ & 3.1 & 130 & 3.0 & .62 \\
\hline
\end{tabular}

${ }^{a}$ From best least squares lines as in Fig. 5.

${ }^{b}$ Correlation coefficient $=0.90$; in the other cases the correlation coefficient was greater than 0.96 .

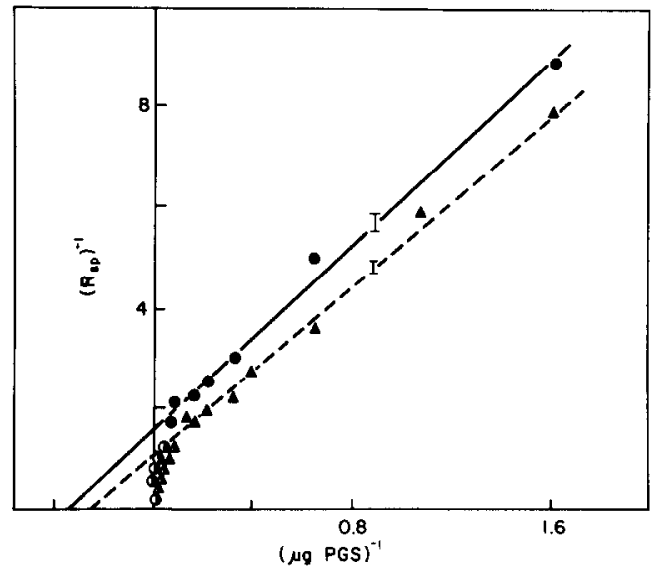

FIG. 5. Relation of the reciprocal of specific retardation of collagen gelation to the reciprocal of the concentration of PGS which affected the retardation. In one series of experiments the concentration of collagen was $1.2 \mathrm{mg} / \mathrm{ml}, 0$, and in the other series of experiments it was $0.6 \mathrm{mg} / \mathrm{ml}, \Delta$. The concentration of PGS was as micrograms per milliliter. The vertical bars indicate the standard error of estimate. Values for the intercepts at the abscissa and ordinate for each line are given in Table II.

a precise determination of $R_{\mathrm{sp}}$ at low concentrations of PGS, nevertheless the results suggest that the change in $\Delta A_{\mathrm{sp}}$ and the initial change in $R_{\mathrm{sp}}$ are related. This relationship is shown in Fig. 6, where the data from the experiments as shown in Figs. 2 and 4 are replotted. For all experiments in which the ratio of PGS to collagen was less than $25 \mu \mathrm{g} / \mathrm{mg}, \Delta A_{\text {sp }}$ was proportional to $R_{\mathrm{sp}}$ (solid symbols). Whereas, for ratios greater than $25 \mu \mathrm{g} / \mathrm{mg}$ there was no correlation and, in general, $R_{\mathrm{sp}}$ continued to increase while $\Delta A_{\mathrm{sp}}$ tended to decrease. It is noteworthy that at high concentrations of PGS the gels were

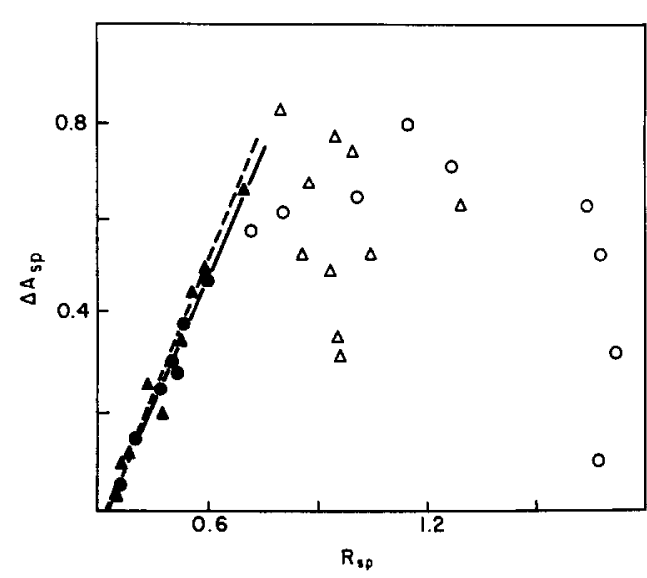

Fig. 6. Relation of specific change in absorbance to specific retardation when collagen fibrils formed in the presence of PGS at $37^{\circ} \mathrm{C}$. The solid symbols are for experiments in which the concentration of PGS was less than $30 \mu \mathrm{g} / \mathrm{mg}$ of collagen, whereas the unfilled symbols are for concentrations of PGS greater than $30 \mu \mathrm{g} / \mathrm{mg}$ of collagen. In one series of experiments the concentration of collagen was 0.6 $\mathrm{mg} / \mathrm{ml}, \Delta$ and $\Delta$, and in the other $1.2 \mathrm{mg} / \mathrm{ml}, 0$ and o.

not of uniform consistency, as was also observed by Toole and Lowther (12).

The Effect of Preparations of Proteoglycans on $\Delta A_{s p}$ and $R_{s p}$

Chondroitin sulfate peptides produced by treatment of the PGS from bovine nasal cartilage with papain, trypsin or cathepsin $D$ had no effect on the absorbance of the collagen gels and they did not retard their formation. The results in the presence of these derivatives, even at high concentrations, $1-2 \mathrm{mg} / \mathrm{ml}$, were not detectably different from the results obtained when collagen alone was used. The protein core 
isolated from the PGS of bovine nasal septa, which contains keratan sulfate (19), and the protein core isolated from the PGS of the rat chondrosarcoma, which does not contain keratan sulfate $(16,29)$, also did not alter the parameters of absorbance and retardation. However, as described below, such preparations of the protein core did bind to collagen when collagen fibrils were forming.

In contrast, aggregated proteoglycan preparations (PGC), when used at equivalent concentrations (hexuronic acid), were as effective as PGS in increasing both $\Delta A_{\mathrm{sp}}$ and $R_{\text {sp }}$ (Figs. 2 and 4). Furthermore, this was the case whether Method $A$ or Method $B$ was used and whether the PGC was derived from bovine nasal septa or the rat chondrosarcoma. Reduced and alkylated PGS also was as effective as unaltered PGS even though such treatment abolishes the ability of PGS molecules to aggregate (15). Moreover, cyanogen bromidetreated PGS retarded the gelation of collagen.

On the basis of the elution volumes $\left(K_{\mathrm{av}}\right.$ values) when the above preparations were permeated through Sepharose columns, it is evident that $\Delta A_{\mathrm{sp}}$ and $R_{\mathrm{sp}}$ depend to a large extent on the size of the polysaccharide-peptide fragments, as was already suggested by Mathews and Decker (11).

\section{Binding of ${ }^{35} \mathrm{~S}$-labeled PGS and ${ }^{3} \mathrm{H}$-labeled PGS Core to Collagen}

Studies on the binding of PGS were done using $\left[{ }^{35} \mathrm{~S}\right]$ sulfate-labeled PGS from the Swarm rat chondrosarcoma. The chemical and physical characteristics of this PGS are very similar to those of the PGS from bovine nasal septa (16), except that the chondrosarcoma PGS has no keratan sulfate and contains only chondroitin-4-sulfate. When the formation of collagen fibrils was assessed in the presence of varying amounts of the PGS from the Swarm rat chondrosarcoma, the results were indistinguishable from those obtained in the presence of the PGS from the bovine nasal septa. In the experiments in which ${ }^{35} \mathrm{~S}$ labeled PGS was used, the collagen fibrils were compacted by centrifugation. The radioactivity in the supernatant solutions was determined; the results are shown in Fig. 7. For three different collagen concentrations, the amount of free PGS was very small (less than $2 \%$ ) until about $180 \mu \mathrm{g}$ of PGS/mg of collagen was added. When more than this amount of PGS/mg of collagen was added, this additional PGS was not bound. With an average molecular weight of $2.5 \times 10^{6}$ for the PGS (30), this gives a ratio of 1 molecule of PGS to 25-30 molecules of collagen. The data also indicate that all of the PGS molecules are capable of binding to collagen, provided the PGS is present as the fibrils of collagen form. If collagen fibrils were formed in the absence of PGS and if they were subsequently suspended in solutions containing different amounts of ${ }^{35} \mathrm{~S}$-labeled PGS, as described in Materials and Methods, no ${ }^{35}$ S-labeled PGS was bound by the fibrils (solid diamonds in Fig. 7). Similarly, if collagen fibrils were formed in the presence of $30 \mu \mathrm{g}$ of unlabeled PGS/mg of collagen, significantly below saturation but where $\Delta A_{\mathrm{sp}}$ is markedly increased (Fig. 2), subsequently added ${ }^{35} \mathrm{~S}$-labeled PGS was not bound to the preformed fibrils (unfilled

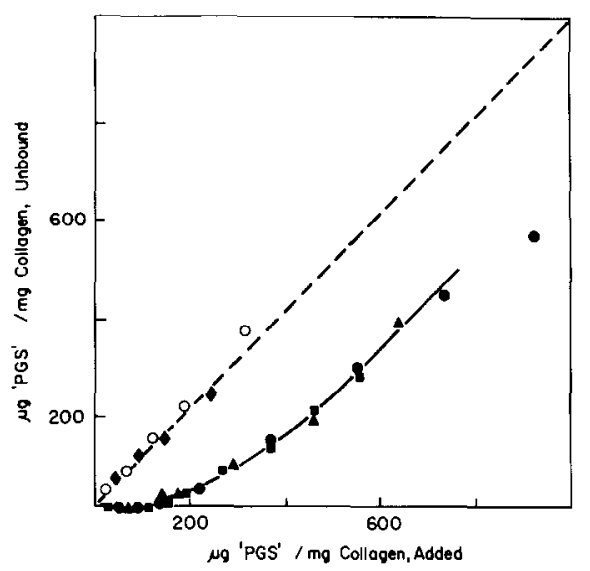

FIG. 7. Binding of ${ }^{35} \mathrm{~S}$-labeled PGS to collagen. The amounts of ${ }^{35} \mathrm{~S}-$ labeled PGS bound to collagen fibrils when the solutions contained $0.6,0.9$, or 1.2 $\mathrm{mg}$ of collagen $/ \mathrm{ml}$ are indicated by $\boldsymbol{\omega}$ or $\boldsymbol{\Delta}$, respectively. The data obtained when ${ }^{35}$ S-labeled PGS was added after collagen fibrils had been formed in the absence of PGS, $\bullet$, or in the presence of $30 \mu \mathrm{g}$ of unlabeled PGS/ml, $O$, indicate that no ${ }^{35} \mathrm{~S}$-labeled PGS was bound under these conditions. In the latter two experiments, and $O$, the initial concentration of collagen was $1.2 \mathrm{mg} / \mathrm{ml}$. 
circles in Fig. 7). Conversely, when collagen fibrils were formed in the presence of saturating amounts of ${ }^{35} \mathrm{~S}$-labeled PGS, the labeled PGS was released only to a limited extent on incubation of the fibrils in solutions containing relatively high concentrations of unlabeled PGS. For example, only $25 \%$ of the ${ }^{35} \mathrm{~S}-$ labeled PGS was released in $16 \mathrm{~h}$ at $37^{\circ} \mathrm{C}$ when such fibrils were present in a solution which contained $1 \mathrm{mg}$ of unlabeled PGS/mg of collagen. In the absence of unlabeled PGS such fibrils on incubation for the same period of time at $37^{\circ} \mathrm{C}$ released $12 \%$ of the bound ${ }^{35} \mathrm{~S}-\mathrm{la}$ beled PGS.

The chondroitin sulfate chains isolated from papain digests of ${ }^{35}$ S-labeled PGS did not bind to collagen (unfilled squares of Fig. 8). However, the protein core of the rat chondrosarcoma, which does not retard the gelation of the collagen solutions and does not have an effect on the absorbance of the gels, was bound by the collagen fibrils during their formation (circles in Fig. 8). The equivalent PGS concentrations ('PGS') were calculated on the basis of protein content in reference to the protein content of the PGS before treatment with the chondroitinase ABC.

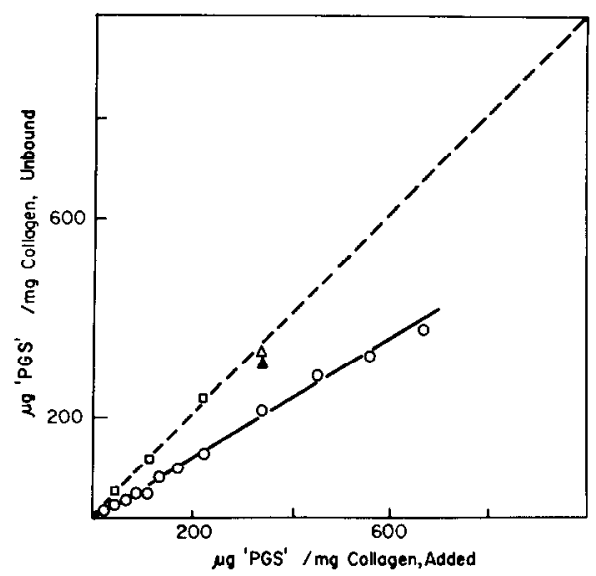

Fig. 8. Binding of $\left[{ }^{3} \mathrm{H}\right]$ serine-labeled protein core and $\left.{ }^{35} \mathrm{~S}\right]$ sulfate-labeled chondroitin sulfate. Collagen fibrils were formed at $37^{\circ} \mathrm{C}$ from solutions of $1.2 \mathrm{mg}$ of collagen $/ \mathrm{ml}$ in the presence of ${ }^{35} \mathrm{~S}$-labeled chondroitin sulfate, $\square$, or ${ }^{3} \mathbf{H}$-labeled protein core, 0 . Collagen fibrils were also formed in the absence of the protein core and then incubated at $37^{\circ} \mathrm{C}$ in the presence of ${ }^{3} \mathrm{H}$-labeled core for $4 \mathrm{~h}, \Delta$, or $18 \mathrm{~h}, \Delta$. The data are given in equivalent concentrations of PGS.
Although the protein core was not bound as strongly to the collagen fibrils as was the intact PGS (compare Fig. 7 with Fig. 8), comparable numbers of the protein-core molecules were bound when the proteincore concentration was high. Further, as was the case when intact PGS was used, once the collagen fibrils were formed in the absence of the protein core, the collagen fibrils were incapable of binding the protein-core molecules (triangles in Fig. 8). The extent to which the protein-core molecules were bound was not altered by the presence of unlabeled, intact PGS up to 1 $\mathrm{mg} / \mathrm{mg}$ of collagen. Thus, it is possible that the protein core and the intact PGS molecules bind to different sites on the collagen fibrils and the PGS does not compete for the site(s) at which the protein core is bound.

\section{The Effect of Adding PGS to Solutions of Collagen During the Lag Phase}

The kinetics of fibril formation in a series of identical solutions of collagen, 1.2 $\mathrm{mg} / \mathrm{ml}$, to which the same amount of PGS in $50 \mu$ l of $1 \times$ buffer was added at different times during incubation at $37^{\circ} \mathrm{C}$ were as shown in Fig. 9. When an additional $50 \mu \mathrm{l}$ of buffer alone was added at $5 \mathrm{~min}$, the results were identical to the results obtained when the buffer was added at time zero. When $150 \mu \mathrm{g}$ of PGS was added after $3.3 \mathrm{~min}$ at $37^{\circ} \mathrm{C}$ both $R_{\text {sp }}$ and $\Delta A_{\text {sp }}$ were altered. At this time, then, PGS was capable of both delaying nucleation and affecting the organization of the fibrils. However, when $150 \mu \mathrm{g}$ of PGS was added after 6.7 min at $37^{\circ} \mathrm{C}, R_{\text {sp }}$ was only slightly affected but $\Delta A_{s p}$ was still markedly affected.

\section{DISCUSSION}

The data described in this report show that collagen fibrillogenesis in solutions at approximately physiological ionic strength and $\mathrm{pH}$ is markedly altered in the presence of very small amounts of PGS or PGC. As the proteoglycan concentrations increase up to $50 \mu \mathrm{g} / \mathrm{mg}$ of collagen, the curves for the parameters $\Delta A_{\text {sp }}$ and the initial phase of $R_{\mathrm{sp}}$ exhibit the characteristic hyperbolic shape that is observed for 


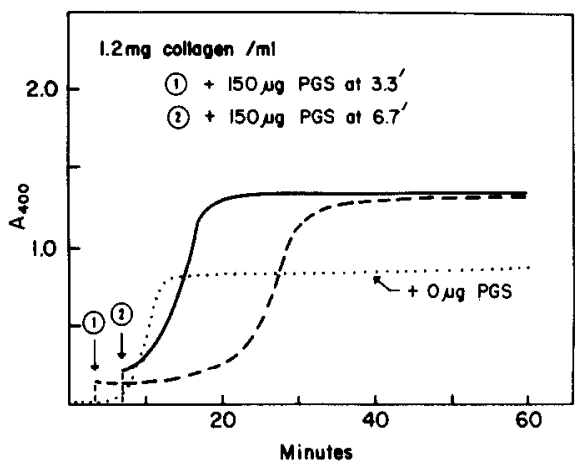

FIG. 9. The effect of adding PGS to solutions of collagen during the lag (nucleation) phase. After incubation at $37^{\circ} \mathrm{C}$ for $3.3 \mathrm{~min},---$, or $6.7 \mathrm{~min},--$, $150 \mu \mathrm{g}$ of PGS in $50 \mu \mathrm{l}$ of $1 \times$ buffer was added. When $50 \mu \mathrm{l}$ of $1 \times$ buffer was added to an identical sample at $5.5 \mathrm{~min}$, the collagen fibrils formed as indicated by $\cdots$.

saturation curves of simple ligand-protein interactions. Both parameters were halfsaturated at 3-5 $\mu \mathrm{g}$ of PGS $/ \mathrm{ml}$, independent of collagen concentrations from $0.3-1.2$ $\mathrm{mg} / \mathrm{ml}$, and the maximum value for $\Delta A_{\mathrm{sp}}$ occurred at 50-60 $\mu \mathrm{g}$ of PGS $/ \mathrm{mg}$ of collagen over the same range of collagen concentrations. Throughout this range of proteoglycan to collagen ratios, all of the PGS molecules become tightly bound into the final fibril structure, provided that they are present before the fibril growth phase occurs. It is highly probable that this binding is a critical factor in the variation of the kinetic parameters. Saturation of binding, however, required much higher ratios of PGS to collagen, $150-200 \mu \mathrm{g} / \mathrm{mg}$, which is approximately the ratio at which saturation of the second phase of $R_{\mathrm{sp}}$ parameter was observed. Fibrils formed at these higher ratios contain about 1 PGS molecule for every 25-30 collagen molecules. Toole and Lowther (12) also showed that maximal retardation of fibrillogenesis occurred at about these ratios. They showed additionally that the initial increment of absorbance at $400 \mathrm{~nm}$ observed immediately after adding proteoglycan to collagen solutions at $4^{\circ} \mathrm{C}$ correlated with the extent of subsequent retardation of gelation. This increment in absorbance was caused by an interaction between the proteoglycan molecules and a proportional amount of collagen up to saturation that yielded com- plexes of much smaller size than fibrils but still large enough to be removed from solution by centrifugation. Thus, while the second phase of retardation appears to correlate with the extent of binding of proteoglycan into fibrils above $50 \mu \mathrm{g}$ of PGS/mg of collagen $\Delta A_{\mathrm{sp}}$ does not and, in fact, tends to decrease. Possibly, at the higher proteoglycan levels, such physical characteristics of the PGS molecules as their exclusion volumes influence the final organization of the fibrils and, hence, $\Delta A_{\mathrm{sp}}$ to a greater extent than at lower proteoglycan levels.

The binding data in this report are consistent with those reported by Öbrink and Wasteson (31), who, using glutaraldehydefixed collagen gels for chromatography, found that the electrostatic interaction of chondroitin sulfate and proteoglycans with collagen was related, among other things, to the size of the macromolecules. This idea was subsequently extended by Öbrink $(32,33)$ by studies on the interaction of collagen from lathrytic rats and a variety of glycosaminoglycans and proteoglycans. The results of these studies suggested additionally that the properties of the polysaccharide chains were of importance for the mode of reaction between the collagen and proteoglycans.

The binding data discussed in this report are also consistent with those described recently by Greenwald et al. (34). They covalently linked soluble collagen from rat tail tendon to Sepharose 4B. The bound collagen resisted digestion with pepsin which suggested that the molecules retained most of their native structure. At $\mathrm{pH} 7$ and ionic strengths less than 0.17 , intact PGS molecules were significantly retarded on the column, and below 0.10 they could not be eluted. Chondroitin sulfate did not bind, whereas core molecules isolated from chondroitinase digests of PGS were significantly retarded under the same conditions. If the collagen molecules that were bound to the Sepharose matrix were widely separated, these results would suggest that the PGS molecules can bind to individual or relatively few collagen molecules.

As was suggested by Mathews and 
Decker (11), the size of the proteoglycan molecules or their derivatives appears to be a major factor for affecting fibrillogenesis. Intact PGS, aggregated PGC, reduced and alkylated PGS and cyanogen bromidetreated PGS all contain essentially intact polysaccharide attachment regions of the protein core with full complements of chondroitin sulfate chains and all were equally effective in altering kinetic parameters. Individual chondroitin sulfate chains, the larger trypsin fragments with one to eight chondroitin sulfate chains per peptide (20) and the slightly larger cathepsin D fragments had no effect. The core molecules, while capable of binding into the forming fibrils, did not alter the kinetic parameters. The presence or absence of keratan sulfate in the proteoglycan molecules did not change their effectiveness in altering fibrillogenesis in any detectable way.

Recently, Trelstad (35) examined collagen samples that were isolated at various times during the pregrowth or nucleation phase of fibrillogenesis in vitro. His electron microscopic observations suggest that the mechanism for nucleation in collagen solutions involves a successive end-to-end elongation of small collagen aggregates, about $2-5 \times 10^{3} \AA$ long and $50-100 \AA$ wide, into long, thin filaments. The results of the experiment in which PGS was added to collagen solutions at different times during the nucleation phase (Fig. 9 above) suggest that the proteoglycan molecules, if present initially, can significantly retard but do not prevent the end-to-end assembly of these small "nucleation" aggregates. However, when the PGS was added late in the nucleation phase, presumably after many of the thin filaments had formed, it was still bound and it still altered the final organization of the fibrils as shown by the change in $\Delta A_{s p}$, but it did so without appreciably retarding the time at which the growth phase occurred. Proteolgycan molecules, then, appear to have two distinct effects on fibrillogenesis; they retard the assembly of collagen molecules if present early enough, and they alter the final fibril organization. ${ }^{5}$

\footnotetext{
5 Preliminary observations with an electron microscope of collagen fibrils formed in the presence of
}

Myers et al. (36) in their electron microscopic studies of connective tissues observed collagen fibrils interlinked by very thin filaments. Such thin filaments were less frequently seen if the tissues were extracted with $4 \mathrm{~m}$ guanidinium chloride. They suggested that the thin filaments are proteoglycans. Their model is reminiscent of the model proposed by Mathews (37) on the basis of results obtained when mixtures of collagen and proteoglycans were analyzed electrophoretically. The model proposed by Mathews $(37,38)$ emphasizes electrostatic forces as playing a major role in the interaction of proteoglycans with collagen.

The results in the present report suggest that the effect of PGS on collagen fibrillogenesis in vitro is related to the availability of a limited number of binding sites on collagen filaments as they are being organized into collagen fibrils. The interaction of the PGS and collagen is probably mainly due to electrostatic forces. However, at high concentrations of PGS, molecular-entanglement and excluded-volume effects might additionally be involved.

\section{ACKNOWLEDGEMENT}

The authors are grateful to Dr. Sylvia FittonJackson, Strangeways Research Laboratory, Cambridge, England, where some of the experiments were done while one of us (D.D.D.) was on leave.

\section{REFERENCES}

1. Meyer, K., Palmer, J. W., and Smyth, E. M. (1973) J. Biol. Chem. 119, 501-506.

2. Meyer, K., and Smyth, E. M. (1937) J. Biol. Chem. 119, 507-510.

3. Vanamee, P., and Porter, K. R. (1951) J. Exp. Med. 94, 255-268.

4. JACKSON, D. S., AND FESSLER, J. H. (1955) $N a$ ture (London) 176, 69-70.

5. Gross, J., Highberger, J. H., ANd SchmitT, F. O. (1955) Proc. Nat. Acad. Sci. USA 41, 1-7.

6. Gross, J. (1956) J. Biophys. Biochem. Cytol. Suppl. 2, 261-274.

small amounts of PGS, 25-60 $\mu \mathrm{g}$ per $\mathrm{mg}$ of collagen, suggest that the increase in $\Delta A_{s p}$ observed in the presence of PGS is not simply caused by a change in the average width of the fibrils. Additionally, fibrils formed in the presence of PGS often show large, ropy structures in which several individual collagen fibrils are coiled about each other. 
7. Gross, J., AND Kirk, D. (1958) J. Biol. Chem. 233, 355-360.

8. Wood, G. C., AND KeECH, M. K. (1960) Biochem. J. 75, 588-598.

9. Wood, G, C. (1960) Biochem. J. 75, 605-612.

10. KeECH, M. I. (1961) J. Biophys. Biochem. Cytol. 9, 193-209.

11. Mathews, M. B., AND Decker, L. (1968) Biochem. J. 109, 517-526.

12. ToOle, B. P., AND Lowther, D. A. (1968) Biochem. J. 109, 857-866.

13. Lowther, D. A., ANd Natarajan, M. (1972) Biochem. J. 127, 607-608.

14. Piez, K. A., Eigner, E. A., And Lewis, M. S. (1963) Biochemistry 2, 58-66.

15. Sajdera, S. W., and Hascall, V. C. (1969) $J$. Biol. Chem. 244, 77-87.

16. Oegema, T., Hascall, V. C., and DziewiatKowsKI, D. D. (1975) J. Biol. Chem. 250, 6151-6159.

17. HeINEgÅRd, D. (1973) Chem. Scr. 4, 199-201.

18. Antonopoulos, C. A., Gardell, S., Szirmai, J. A., And De Tyssonk, E. (1964) Biochim. Biophys. Acta 83, 1-19.

19. Hascall, V. C., and Riolo, R. L. (1972) J. Biol. Chem. 247, 4529-4538.

20. Heinegard, D., and Hascall, V. C. (1974) Arch. Biochem. Biophys, 165, 427-441.

21. BARRETt, A. J. (1970) Biochem. J. 117, 601-607.

22. Ikenaka, T., Ishiguro, M., Emura, J., KaufMANN, H., Isemura, S., BaUer, W., AND SснмID, K. (1972) Biochemistry 11, 38173829 .

23. Neuman, R. E., and Logan, M. A. (1950) J.
Biol. Chem. 184, 299-306.

24. Spackman, D. H., Stein, W. H., and Moore, S. (1958) Anal. Chem. 30, 1190-1210.

25. Dzie wiatkowski, D. D., Hascall, V. C., and Riolo, R. L. (1972) Anal. Biochem. 49, 550558.

26. Bitter, T., and Muir, H. (1962) Anal. Biochem. 4, 330-334.

27. Lowry, O. H., Rosebrough, N. J., FARR, A. L., AND RaNdall, R. J. (1951) J. Biol. Chem. 193, 265-275.

28. Lineweaver, H., and Burk, D. (1934) J. Amer. Chem. Soc. 56, 658-666.

29. Chol, H. U., Meyer, K., ANd Swarm, R. (1971) Proc. Nat. Acad. Sci. USA 68, 877-879.

30. Hascall, V. C., and Sajdera, S. W. (1970) J. Biol. Chem. 245, 4920-4930.

31. Öbrink, B., ANd Wasteson, $\AA$. (1971) Biochem. J. 121, 227-233.

32. Öbrink, B. (1973) Eur. J. Biochem. 33, 387-400.

33. Öbrink, B. (1973) Eur. J. Biochem. 34, 129-137.

34. Greenwald, R. A., Schwartz, C. E., and CanTOR, J. O. (1975) Biochem. J. 145, 601-605.

35. Trelstad, R. L. (1975) in Extracellular Matrix Influences on Gene Expression (Slavkin, H., and Greulich, R., eds.), pp. 331-340. Academic Press, New York.

36. Myers, D. B., Highton, T. C., and Rayns, D. G. (1973) J. Ultrastruct. Res. 42, 87-92.

37. Mathews, M. (1965) Biochem. J. 96, 710-716.

38. Mathews, M. B. (1970) in Chemistry and Molecular Biology of the Intercellular Matrix (Balazs, E. A., ed.), Vol. 2, pp. 1155-1169, Academic Press, London. 